\title{
Exploration of indigenous strains of the green muscardine fungus from soils and their pathogenicity against the tobacco caterpillar, Spodoptera litura (Fabricius) (Lepidoptera: Noctuidae)
}

\author{
R. Dhanapal ${ }^{1,2^{*}}$, D. V. Sai Ram Kumar ${ }^{2}$, R. Lakshmipathy ${ }^{3}$, C. Sandhya Rani ${ }^{2}$ and V. Manoj Kumar ${ }^{4}$
}

\begin{abstract}
In the recent years, the keen interest has been increased towards biological control-based management practices using entomopathogenic fungi (EPF) for the control of many economically important insects. In this management practices, selection of right strains of EPF is an important criteria to control the target pests in effective manner. In this context, this research work was formulated to find out environmentally effective strains of EPF in the soils of costal districts of Andhra Pradesh. Out of 135 soil samples collected, 8 soil samples yielded 8 strains of Metarhizium anisopliae. Among all $8 \mathrm{M}$. anisopliae isolates, the least median lethal concentration $\left(\mathrm{LC}_{50}\right)$ for 2 nd instar of the tobacco caterpillar, Spodoptera litura (Lepidoptera: Noctuidae) was $1.24 \times 10^{5}$ spores $\mathrm{ml}^{-1}$ in $\mathrm{M}-7$, followed by $1.72 \times$ $10^{5}$ spores $\mathrm{ml}^{-1}$ in $\mathrm{M}-5$ and $1.86 \times 10^{5}$ spores $\mathrm{ml}^{-1}$ in M-4 in an increasing order. Likewise, the median lethal time $\left(L T_{50}\right)$ values of different isolates of EPF against $2^{\text {nd }}$ instar of S.litura were calculated for a uniform highest dose of 1 $\times 10^{8}$ spores $\mathrm{ml}^{-1}$. Among all $8 \mathrm{M}$. anisopliae isolates, the lowest $L T_{50}$ was observed as 186.44 hours post infection (hpi) with M-5 and 189.34 hpi with M-7.
\end{abstract}

Keywords: Metarhizium anisopliae, Spodoptera litura, Soil, Green muscardine fungus

\section{Background}

Soil is an important reservoir for entomopathogenic fungi (EPF) as it protects them from degradation by UV light. The important EPF were found in the order of deuteromycetes and entomopthorales. Fungal agents are the most potential group of bio control agents against insect pests as they infect their host through the cuticle. They have wide insect host ranges, widely distributed (Rohrlich et al., 2018), and the potential candidate to regulate insect pest populations is well established in the tropics (Maniania, 2002) and temperate

\footnotetext{
* Correspondence: dhanapal.agri@gmail.com

'Department of Entomology, Institute of Agriculture Science, Banaras Hindu University, Varanasi, Uttar Pradesh 221005, India

${ }^{2}$ Department of Entomology, Agricultural College, Bapatla, Guntur, Andhra Pradesh 522101, India

Full list of author information is available at the end of the article
}

environments (Meyling and Eilenberg, 2007). EPF-based biopesticides show potential strategy for insect pest management to combat the insecticide-related problems. In nature, many of the EPF species have strains, which having different survival ability and virulence. The genera such as Entomophthora, Beauveria, Metarhizium, or Aspergillus are most commonly reported in nature (Mugonza et al., 2020). The EPF, Metarhizium anisopliae (Metchnikoff) Sorokin has been isolated from 200 insects' species including the orders, Lepidoptera, Coleoptera, Orthoptera, and Hemiptera. The genetic diversity has been reported in M. anisopliae and Beauveria bassiana (Sevim et al., 2012), and their virulence influences to various hosts, environmental conditions, conidial survival, and competitive saprophytic ability can profoundly influence their 
virulence. The strains can be differentiated by their levels of proteases, chitinases, and lipases (Varela and Morales, 1996).

Spodoptera litura (Fabricius) (Lepidoptera: Noctuidae), commonly known as tobacco caterpillar, is one of the most destructive insect pests of cauliflower, groundnut, cotton, tomato, cabbage, and other cruciferous crops (Anand and Tiwary, 2009). Hence, for combating this pest, one such alternative way is the usage of microbial pesticides with EPF which have key role in sustainable pest management program. Due to the development of resistance to insecticides and concerns over the deleterious effects of insecticides on environmental and human safety, exploring and developing microbial control agents for use in integrated control of insect pests have provided an impetus need (Inglis et al., 2001). Use of entomopathogens as biocontrol agents have several advantages compared with conventional insecticides with respect to the low cost, high efficiency, safety to beneficial organisms, reduction of residues in environment, and increased biodiversity in human-managed ecosystems (Zimmerman, 1986). Control of insect pests by using local isolates of EPF is an effective method to combat insecticide resistance and resurgence and these local isolates also have more chances of more survival and persistence with better adaptability to local climatic conditions. The success of insect control using EPF is based on correct selection of strain which have adapted to climatic conditions. In Andhra Pradesh, the alien strains EPF were used for insect control. So, that the failure of EPF occurs.

In this context, the present research was formulated to identify efficient strains of Metarhizium anisopliae from soil and their pathogenicity against $S$. litura under laboratory conditions.

\section{Material and methods}

\section{Isolation of entomopathogenic fungi from soil}

The soil was sampled from diverse habitats such as agricultural land, forest land, and barren/grass land from different locations of North Coastal, Mid Coastal, and South Coastal districts of Andhra Pradesh, India. Totally, 135 soil samples were collected at 9 districts. Four soil samples from each field were taken at $10 \mathrm{~cm}$ deep from different selected/representative areas of the Coastal Andhra Pradesh, India. EPF were isolated using the greater wax moth "Galleria bait method" (Zimmerman, 1986). Before exposing to G. mellonella for fungal isolation, soil samples were sieved and debris were removed. The fine particles of soil were collected and sprinkled water to create favorable condition for fungus. Approximately, $80 \mathrm{~g}$ soil was weighed and transferred to small sterile plastic disposable containers. Five larvae of $G$. mellonella of about final instar larvae were released into each container and incubated for approximately 14 days under laboratory conditions. The larvae were examined daily from 3rd day after inoculation. Diseased and moribund or mummified larvae were retrieved from the container for isolation of the fungi. The soil particles, found attached to the infected cadavers were removed, and cadavers were washed by $2 \%$ sodium hypochloride $(\mathrm{NaOCl})$ and serially washed by distilled water. Then, these cadavers were transferred to sterile Petri plates and incubated for 3-4 days on moist filter paper for sporulation of fungi in B.O.D. incubator at $25 \pm 2{ }^{\circ} \mathrm{C}$ with $70-80 \%$ R.H. The infected cadavers, which having mycelia growth, were surface sterilized by $2 \%$ sodium hypochloride $(\mathrm{NaOCl})$ solution for $2 \mathrm{~min}$ and serially washed with sterile distilled water for 3 times and then was placed over a sterilized blotter paper for removing residual water. The surface sterilized cadavers were then transferred to Potato Dextrose Agar (PDA) medium. These plates were incubated at $25 \pm 2{ }^{\circ} \mathrm{C}$ in B.O.D. incubator with $70-80 \%$ R.H.; after that the observations on fungal growth was examined daily. The fungi were purified by the single hyphal tip method of Rangaswami, 1971.

\section{Bio-efficacy of the tested pathogens}

S. litura was used for testing the pathogenicity of isolated EPF. S. litura was reared on natural host castor under laboratory conditions. The 2nd instar larvae of $S$. litura were immersed individually for $30 \mathrm{~s}$ in 5 different concentrations $\left(1 \times 10^{4}, 1 \times 10^{5}, 1 \times 10^{6}, 1 \times 10^{7}\right.$, and $1 \times 10^{8}$ conidia $\mathrm{ml}^{-1}$ ) of fungal spore suspensions of isolated EPF prepared by a serial dilution method (Asi et al., 2013). In control, the larvae were treated only by $0.02 \%$ Tween 80 mixed with water. In order to remove the excess moisture, the treated larvae were allowed to crawl freely on a tissue paper in a Petri dish. After air drying, the treated larvae were fed with fresh and clean castor leaves in the laboratory $\left(27 \pm 2{ }^{\circ} \mathrm{C}\right.$ and $\left.60-70 \% \mathrm{RH}\right)$. Leaves were washed twice with water and air dried for $15 \mathrm{~min}$. At $24 \mathrm{~h}$ interval, the leaves were periodically replaced with fresh ones. The dead larvae were incubated on moist filter paper for confirmation of EPF sporulation. Dead larvae were removed daily from the Petri plates. Thirty larvae/treatment with 3 replications were maintained in each experiment. The data on larval mortalities were recorded daily for 14 days after treatment (DAT). Mortality was recorded in the control category also for Abbott's correction (Abbott, 1925). The mortality values after Abbott's correction formula were only subjected to statistical analysis.

\section{Statistical analysis}

The $\mathrm{LC}_{50}$ and $\mathrm{LT}_{50}$ values were derived from logarithmic calculations (Finney, 1984) using the multiple linear program. The data was analyzed by probit analysis using analysis of variance (ANOVA) technique (Gomez and Gomez, 1984) using the SPSS software. 
Table 1 Fungal codes, districts, and habitats of Coastal Andhra Pradesh, India

\begin{tabular}{lll}
\hline Fungal code & District & Habitat \\
\hline $\mathbf{M}-\mathbf{1}$ & Srikakulam & Orchard land \\
$\mathbf{M - 2}$ & Vizianagaram & Agricultural land \\
$\mathbf{M}-\mathbf{3}$ & Visakhapatnam & Agricultural land \\
$\mathbf{M}-\mathbf{4}$ & Vizianagaram & Agricultural land \\
$\mathbf{M - 5}$ & Krishna & Barren land \\
$\mathbf{M - 6}$ & East Godavari & Agricultural land \\
$\mathbf{M - 7}$ & Vizianagaram & Agricultural land \\
$\mathbf{M - 8}$ & Nellore & Barren land \\
\hline
\end{tabular}

\section{Results and discussion}

Among 135 soil samples collected, 8 isolates of green muscardine fungus, Metarhizium anisopliae, were isolated. The 8 fungal isolates were designated as $\mathrm{M}-1, \mathrm{M}-2$, M-3, M-4, M-5, M-6, M-7 and M-8 (Table 1). M. anisopliae showed a significant occurrence in majority of the soil samples. Mostly, the EPF were isolated from agricultural land, followed by barren land in the order of occurrence of fungi in the soil, and orchard/forest land occupied the last rank in the sequence. Identification of EPF was undertaken depending upon colony morphology, size, and shape of conidia. The colony of $M$. anisopliae was white in color during initial stage and then changed into dark green during sporulation. The conidiophores were in compact patches. The individual conidiophores were broadly branched, densely intertwined, and conidiogenous cells with their rounded to conical apices which arranged in dense hymenium. Conidia were aseptate, cylindrical, or ovoid forming chains usually aggregated into prismatic or a solid mass of parallel chains. Identity of the isolates of different EPF was also confirmed by the $\mathrm{Na}$ tional Bureau of Agricultural Insect Resources (NBAIR), Bengaluru, India. Several authors reported that M. anisopliae is dominant in the soil from cultivated fields; however, it was rarely found from natural habitats (Meyling et al., 2011). According to Sun (2008), it is the most tolerant species to agricultural interventions, such as plowing and usage of pesticides. It was also found to be tolerant to periodic absence of potential host in the environment. $M$. anisopliae was more common in soils in northern countries with more humid and cooler climates such as Norway (Klingen et al., 2002), Switzerland (Keller et al., 2003), and Pacific Northwest in the USA (Bruck, 2004). It has also been observed that the conidia of $M$. anisopliae can persist longer without repeated infection of hosts than $B$. bassiana (Sun, 2008), whereas the persistence of $B$. bassiana in the same heavily cultivated soils was found to be low due to lack of a suitable host species and the same hypothesis was supported by Klingen et al. (2002), who demonstrated that EPF occurred more commonly in soils from organically managed arable fields than with conventional ones, in which synthetic insecticides had greatly reduced the availability of suitable hosts. Apart from their effect on insect hosts, pesticides had deleterious effects on the EPF in the soil, although results from laboratory experiments and field conditions might differ (Clifton et al., 2015). Several studies suggested that some fungal species were more tolerant to pesticides than others, and $M$. anisopliae was considered to be more tolerant to pesticides than B. bassiana, which could also explain why the occurrence of $M$. anisopliae is more frequent in cultivated habitats. Similar findings along with a low competitive ability in B. bassiana (Mahot et al., 2019) could account for the greater frequency of occurrence of M. anisopliae in cultivated soils in the present investigation. Sampling of soils in the present study was conducted during the period when the environmental temperature ranged between 25 to $30^{\circ} \mathrm{C}$, and thus, the occurrence of $M$. anisopliae was more from different samples. This result was supported by Pietraszczyk et al. (2013) in which $M$. anisopliae was isolated at the environmental temperature of $25^{\circ} \mathrm{C}$, whereas B. bassiana and I. fumosoroseus were isolated more at the environmental temperature of $20^{\circ} \mathrm{C}$ from Polish soils, which was also proved in laboratory reared conditions by live bait technique at different environmental temperatures.

The parameters such as organic carbon content, organic matter content, and soil texture were highly influencing the occurrence of EPF in the soil samples

Table 2 Spore concentration mortality response of S. litura to different fungal isolates of $M$. anisopliae

\begin{tabular}{|c|c|c|c|c|}
\hline Fungal isolates & Heterogeneity (x2) & Regression equation & $\mathrm{LC}_{50}$ (spores $\mathrm{ml}^{-\mathbf{1}}$ ) & Fiducial limit \\
\hline$\overline{M-1}$ & 1.236 & $y=0.322 x+2.991$ & $1.63 \times 10^{6}$ & $0.35 \times 10^{6}-7.45 \times 10^{6}$ \\
\hline$M-2$ & 0.949 & $y=0.289 x+3.319$ & $6.17 \times 10^{5}$ & $0.11 \times 10^{6}-3.36 \times 10^{6}$ \\
\hline M-3 & 2.237 & $y=0.439 x+2.169$ & $2.99 \times 10^{6}$ & $0.93 \times 10^{6}-9.54 \times 10^{6}$ \\
\hline$M-4$ & 0.979 & $y=0.281 x+3.517$ & $1.86 \times 10^{5}$ & $0.27 \times 10^{5}-3.34 \times 10^{5}$ \\
\hline$M-5$ & 1.698 & $y=0.374 x+3.045$ & $1.72 \times 10^{5}$ & $0.40 \times 10^{5}-7.24 \times 10^{5}$ \\
\hline$M-6$ & 0.575 & $y=0.328 x+3.047$ & $8.41 \times 10^{5}$ & $0.19 \times 10^{5}-9.40 \times 10^{5}$ \\
\hline$M-7$ & 0.338 & $y=0.399 x+2.967$ & $1.24 \times 10^{5}$ & $0.29 \times 10^{5}-5.91 \times 10^{5}$ \\
\hline M-8 & 0.775 & $y=0.387 x+2.462$ & $3.45 \times 10^{6}$ & $0.90 \times 10^{6}-6.31 \times 10^{6}$ \\
\hline
\end{tabular}


Table 3 Time mortality response of $S$. litura to different fungal isolates of $M$. anisopliae

\begin{tabular}{|c|c|c|c|c|}
\hline Fungal isolates & Heterogeneity $\left(x^{2}\right)$ & Regression equation & $\mathrm{LT}_{\mathbf{5 0}}$ (hpi) $^{*}$ at $1 \times 10^{\mathbf{8}}$ spores $\mathrm{ml}^{-\mathbf{1}}$ & Fiducial limit \\
\hline$M-1$ & 20.16 & $y=1.432 x+0.942$ & 209.47 & 190.99-236.35 \\
\hline$M-2$ & 14.84 & $y=1.726 x+0.442$ & 198.92 & 180.69-218.99 \\
\hline$M-3$ & 15.85 & $y=1.741 x+0.415$ & 195.29 & $177.81-214.48$ \\
\hline$M-4$ & 22.49 & $y=1.499 x+0.825$ & 196.50 & $178.37-216.48$ \\
\hline$M-5$ & 16.05 & $y=1.773 x+0.465$ & 186.44 & 169.94-204.54 \\
\hline$M-6$ & 23.80 & $y=1.513 x+0.802$ & 198.51 & $180.14-218.77$ \\
\hline$M-7$ & 15.81 & $y=1.789 x+0.36$ & 189.34 & $172.47-207.86$ \\
\hline$M-8$ & 14.69 & $y=1.667 x+0.563$ & 201.41 & $182.15-222.70$ \\
\hline
\end{tabular}

*hpi- hours post infection

(Uzman et al., 2019 and Moloinyane et al., 2020) whereas the $\mathrm{pH}$ and $\mathrm{EC}$ of the soil samples did not show any significant impact on the occurrence of EPF (Karthick et al., 2013). This might be because of higher cation exchange capacities of the soil with greater organic matter, which are responsible for enhanced adsorption of fungal conidia. Soil samples with greater organic matter support greater diversity and density of arthropod hosts on which the fungi can multiply or rely for their metabolism (Inglis et al., 2001; Klingen and Haukeland, 2006; Sularno et al., 2019). The effects of soil factors (organic matter, clay, sand, silt content, and $\mathrm{pH}$ ) and their geographical location (latitude, longitude and altitude) on the natural occurrence of entomopathogenic fungi have been earlier reported in various studies (Roberts and Leger, 2004; Karthick et al. 2013) wherein, it was reported that the frequency of occurrence was more in soils containing high organic matter and total nitrogen content, whereas, soil $\mathrm{pH}$ and geographical distribution did not influence the occurrence.

Among all $8 \mathrm{M}$. anisopliae isolates, the least median lethal concentration $\left(\mathrm{LC}_{50}\right)$ for 2 nd instar of $S$. litura was $1.24 \times 10^{5}$ spores $\mathrm{ml}^{-1}$ in M-7 followed by $1.72 \times 10^{5}$ spores ml ${ }^{-1}$ in M-5 and $1.86 \times 10^{5}$ spores ml ${ }^{-1}$ in M-4 in an increasing order. Then the remaining isolates of $M$. anisopliae had shown their median lethal concentration at $3.45 \times 10^{6}$ spores ml ${ }^{-1}$ in M-8, $2.99 \times 10^{6}$ spores $\mathrm{ml}^{-1}$ in $\mathrm{M}-3,8.41 \times 10^{5}$ spores $\mathrm{ml}^{-1}$ in M-6, $6.17 \times 10^{5}$ spores $\mathrm{ml}^{-1}$ in $\mathrm{M}-2$, and $1.63 \times 10^{6}$ spores $\mathrm{ml}^{-1}$ in $\mathrm{M}-1$. The values of $\chi^{2}$, regression equation, and fiducial limits corresponding to different $\mathrm{LC}_{50}$ values of different isolates of M. anisopliae are presented in Table 2. The $\mathrm{LT}_{50}$ values of different isolates of EPF against 2nd instar of S.litura were calculated for a uniform highest dose of $1 \times 10^{8}$ spores $\mathrm{ml}^{-1}$. Among all $8 \mathrm{M}$. anisopliae isolates, the lowest $\mathrm{LT}_{50}$ was observed as 186.44 hours post infection (hpi) in M-5 and 189.34 hpi in M-7. The remaining isolates of M. anisopliae had shown their $\mathrm{LT}_{50}$ values as $195.29 \mathrm{hpi}$ with M3, 198.51 hpi with M-6, 198.92 hpi with M-2,196.50 hpi with M-4, 209.47 hpi with M-1, and 201.41hpi with M-8. The values of $\chi 2$, regression equation and fiducial limits corresponding to different $\mathrm{LT}_{50}$ values of different isolates of $M$. anisopliae are presented in Table 3. The median lethal concentrations $\left(\mathrm{LC}_{50}\right)$ and median lethal times $\left(\mathrm{LT}_{50}\right)$ of EPF were determined by reference to $50 \%$ mortality of the 2nd instar $S$. litura larvae after dipping them in fungal spore suspension for few seconds (Asi et al., 2013). Second instar larvae of $S$. litura were sensitive to all dosedependent EPF isolates used in the bioassay. At lower conidial concentrations, the mortality caused by each fungus was low. It increased with higher conidial concentration. Mortalities caused by the EPF also varied significantly at different conidial concentrations against 2nd instar larvae of the insect. Statistical analysis was done, using probit analysis. In the present investigation, the fungal pathogens showed variation in pathogenicity against $S$. litura. Among the 8 fungal isolates, the least $\mathrm{LC}_{50}$ was $1.24 \times 10^{5}$ spores $\mathrm{ml}^{-1}$ in M-7. These intraspecific variations observed in the present studies are in agreement with those reported earlier by Feng and Johnson, 1990 and Wang et al., 2019. When the concentration of fungal spores increased, the corresponding mortality was also increased. Virulence of EPF varied from species to species and strain to strain against S. litura (Dayakar and Kanaujia, 2003 and Lin et al., 2007).

\section{Conclusion}

Through the attempt to isolate indigenous soil strains of EPF. The green muscardine fungus showed a thermo and pesticide tolerance. Among the 8 strains isolated from the soil, the M-7 and M-5 were the most suitable for formulation and field application. Further studies need to be conducted in aspect of formulation and field efficacy of these EPF in insect control.

\section{Acknowledgements \\ Authors wish to highly gratefully thank to Dr. B. Ramanujam, Principal Scientist, NBAIR, Bengaluru for his valuable identification of entomopathogenic fungi.}

\section{Authors' contributions}

The conception and design of the study were done by all authors. RD collected the soil samples from the nine coastal Andhra Pradesh, India, isolated entomopathogenic fungi from soil, analyzed soil physicochemical 
parameters and preparation of the manuscript. DV helped in the pathogenicity of entomopathogenic fungi against tobacco caterpillar. RL and $\checkmark$ authors helped in the identification of entomopathogenic fungi. $C$ helped in the maintenance of Spodoptera litura and Galleria mellonella. All the authors read and approved the manuscript.

\section{Funding}

This work was not supported by any funding body.

\section{Availability of data and materials}

The data and material used during the current study are available from the corresponding author on reasonable request

\section{Ethics approval and consent to participate}

I agree to all concerned regulations.

\section{Consent for publication}

I agree to publish this scientific paper in the EJBPC.

\section{Competing interests}

The author declares that he/she has no competing interests.

\section{Author details}

'Department of Entomology, Institute of Agriculture Science, Banaras Hindu University, Varanasi, Uttar Pradesh 221005, India. ${ }^{2}$ Department of Entomology, Agricultural College, Bapatla, Guntur, Andhra Pradesh 522101, India. ${ }^{3}$ Department of Microbiology, Agricultural College, Bapatla, Guntur, Andhra Pradesh 522101, India. ${ }^{4}$ Department of Plant Pathology, Agricultural College, Bapatla, Guntur, Andhra Pradesh 522101, India.

Received: 27 December 2019 Accepted: 18 March 2020

Published online: 30 March 2020

\section{References}

Abbott WS (1925) A method of computing the effectiveness of an insecticide. J Econ Entomol 18:265-267

Anand R, Tiwary BN (2009) Pathogenicity of entomopathogenic fungi to eggs and larvae of Spodoptera litura, the common cutworm. Biocontrol Sci Techn 19(9):919-929

Asi MR, Bashir MH, Afzal M, Zia K, Akram M (2013) Potential of entomopathogenic fungi for biocontrol of Spodoptera litura Fabricius (Lepidoptera: Noctuidae). J Anim plant Sci 23(3):913-918

Bruck DJ (2004) Natural occurrence of entomopathogens in Pacific Northwest nursery soils and their virulence to the black vine weevil, Otiorhynchus sulcatus (F.) (Coleoptera: Curculionidae). Environ Entomol 33:1335-1343

Clifton EH, Jaronski ST, Hodgson EW, Gassmann AJ (2015) Abundance of soilborne entomopathogenic fungi in organic and conventional fields in the Midwestern USA with an emphasis on the effect of herbicides and fungicides on fungal persistence. PLOS ONE 10:e0133613

Dayakar S, Kanaujia KR (2003) Evaluation of the pathogenicity of Beauveria bassiana, Metarhizium anisopliae and Nomuraea rileyi on different larval stages of tobacco caterpillar, Spodoptera litura (F.). Indian J Plant Prot 31(2):9-12

Feng MG, Johnson JB (1990) Relative virulence of six isolates of Beauveria bassiana (Fungi: Hyphomycetes) on the Russian wheat aphid Diuraphis noxia (Homoptera: Aphididae). Environ Entomol 19:785-790

Finney DJ (1984) Probit analysis. Cambridge University Press, London, p 333

Gomez KA, Gomez AA (1984) Statistical procedures for agricultural research, 2nd edn. International Rice Research Institute, Philippines, p 680

Inglis GD, Goettel MS, Butt TM, Strasser H (2001) Use of hyphomycetous fungi for managing insect pests. In: Butt TM, Jackson C, Magan N (eds) Fungi as biocontrol agents: progress, problems and potential. CAB International, Wallingford, UK, pp 23-69

Karthick RN, Bharani RSA, Ansari MR (2013) Natural occurrence of potential fungal biopesticide Nomuraea rileyi (farlow) samson associated with agriculture fields of Tamil Nadu, India and it's compatibility with metallic nanoparticles. J Biofertilizers Biopest 4(1):2-7

Keller S, Kessler P, Schweizer C (2003) Distribution of insect pathogenic soil fungi in Switzerland with special reference to Beauveria brongniartii and Metarhizium anisopliae. Biocontrol 48:307-319
Klingen I, Eilenberg J, Meadow R (2002) Effects of farming system, field margins and bait insect on the occurrence of insect pathogenic fungi in soils. Agric Ecosyst Environ 91:191-198

Klingen I, Haukeland S (2006) The soil as a reservoir for natural enemies of pest insects and mites with emphasis on fungi and nematodes. In: Eilenberg J, Hokkanen HMT (eds) An ecological and societal approach to biological control. Springer, The Netherlands, pp 145-211

Lin HP, Yang XJ, Gao YB, Li SG (2007) Pathogenicity of several fungal species on Spodoptera litura. Chin J Appl Ecol 18(4):937-940

Mahot HC, Membang G, Hanna R, Begoude DAD, Bagny Beilhe L, Bilong BCF (2019) Laboratory assessment of virulence of Cameroonian isolates of Beauveria bassiana and Metarhizium anisopliae against mirid bugs Sahlbergella singularis Haglund (Hemiptera: Miridae). Afr Entomol 27:86-96

Maniania NK (2002) A low cost contamination device for infecting adult tsetse flies, Glossina spp., with the entomopathogenic fungus Metarhizium anisopliae in the field. Biocontrol Sci Techn 12:59-66

Meyling N, Eilenberg J (2007) Ecology of the entomopathogenic fungi Beauveria bassiana and Metarhizium anisopliae in temperate agroecosystems: potential for conservation biological control. Biol Control 43:145-155

Meyling NV, Thorup-Kristensen K, Eilenberg J (2011) Below- and aboveground abundance and distribution of fungal entomopathogens in experimental conventional and organic cropping systems. Biol Control 59(2):180-186

Moloinyane S, Addison P, Achiano KA, Nchu F (2020) Association between chemical properties of vineyard soils and occurrence of entomopathogenic fungi causing different levels of mortality in Planococcus ficus. BioControl https://doi.org/https://doi.org/10.1007/s10526-019-09989-3.

Mugonza J, Otim M H, Egonyu JP (2020) The comparative virulence of an atoxigenic strain of Aspergillus flavus (Eurotiales: Trichocomaceae) and the commercial ICIPE 69 Metarhizium anisopliae (Hypocreales: Clavicipitaceae) to the bean leaf beetle Ootheca mutabilis (Coleoptera: Chrysomelidae). Int J Trop Insect Sc https://doi.org/https://doi.org/10.1007/s42690-019-00091-w.

Pietraszczyk JJ, Gorska K, Kamionek M, Zawitkowski J (2013) The occurrence of entomopathogenic fungi in the Chojnowski landscape park in Poland. Ann Warsaw Univ Life Sci 52:37-47

Rangaswami G (1971) Diseases of crop plants in India. Prentice Hall of India Pvt. Ltd., New Delhi, p 520

Roberts DW, St. Leger RJ (2004) Metarhizium spp., cosmopolitan insectpathogenic fungi: mycological aspects. Adv Appl Microbiol 54:1-70

Rohrlich C, Merle I, Hassani IM, Verger M, Zuin M, Besse S, Robene I, Nibouche S, Costet $L$ (2018) Variation in physiological host range in three strains of two species of the entomopathogenic fungus Beauveria. PLoS ONE 13:e0199199

Sevim A, Hofte M, Demirbag Z (2012) Genetic variability of Beauveria bassiana and Metarhizium anisopliae var. anisopliae isolates obtained from the Eastern Black Sea Region of Turkey. Turk J Biol 36:255-265

Sularno AE, Fefiani Y (2019) Abundance and diversity of entomopathogenic fungi in Sibolangit conservation forest and Berastagi vegetable land. Int J Lang Res Educ Stud 3(1):127-136

Sun BD, Yu HY, Chen AJ, Liu XZ (2008) Insect associated fungi in soils of field crops and orchards. Crop Protect 27:1421-1426

Uzman D, Pliester J, Leyer I, Entling MH, Reineke A (2019) Drivers of entomopathogenic fungi presence in organic and conventional vineyard soils. Appl Soil Ecol 133:89-97

Varela A, Morales E (1996) Characterization of some Beauveria bassiana isolates and their virulence toward the coffee berry borer Hypothenemus hampei. J Invertebr Pathol 67:147-152

Wang W, Zhou L, Dong G, Chen F (2019) Isolation and identification of entomopathogenic fungi and an evaluation of their actions against the larvae of the fall webworm, Hyphantria cunea (Drury) (Lepidoptera: Arctiidae). BioControl 65:101-111

Zimmermann G (1986) "Galleria bait method" for detection of entomopathogenic fungi in soil. J Appl Entomol 102:213-215

\section{Publisher's Note}

Springer Nature remains neutral with regard to jurisdictional claims in published maps and institutional affiliations. 